\title{
Statins go beyond cardioprotection
}

The long-term 'legacy' benefits of statin therapy may extend beyond a reduction in the risk of cardiovascular events to include protection against infection and respiratory disease. The Anglo-Scandinavian Cardiac Outcomes Trial (ASCOT) investigators have drawn this conclusion on the basis of 11-year follow-up data from British patients enrolled in the lipid-lowering arm of their multicenter, randomized trial. The latest results from this study were reported at the European Society of Cardiology 2011 Congress and published in the European Heart Journal.

ASCOT, was primarily a study of antihypertensive therapy. In addition, $10 \mathrm{mg}$ atorvastatin was compared with placebo in a subgroup of trial participants. The lipidlowering arm of the trial was terminated prematurely in 2002 after atorvastatin was shown to significantly reduce the incidence of the cardiovascular end point. However, patients in both atorvastatin and placebo groups were given the opportunity to continue with atorvastatin therapy until the antihypertensive arm of the trial was concluded in 2005.

During the extended period of follow-up, which ended in December 2010, the number of all-cause deaths and noncardiovascular deaths among 4,605 patients was significantly lower among those who had originally been assigned to atorvastatin (HRs of 0.86 and 0.85 , respectively). The reduction in noncardiovascular deaths was largely driven by a decrease in deaths caused by infection and respiratory illnesses. Cardiovascular mortality was also reduced, although not significantly.

The investigators call for studies to investigate the mechanisms underlying the non-lipid-lowering benefits of statins.

\section{Alexandra King}

Original article Sever, P. S. et al. The Anglo-Scandinavian Cardiac Outcomes Trial: 11-year mortality follow-up of the lipid-lowering arm in the UK. Eur. Heart J. doi:10.1093/ eurheartj/ehr333 